\title{
PARTNERSHIP PRACTICES AND THEIR IMPACT ON VALUE CREATION - REFLECTIONS FROM LEAN MANAGEMENT
}

\author{
Tuuli JYLHÄ ${ }^{\mathrm{a}, *}$, Seppo JUNNILA ${ }^{\mathrm{a}}$ \\ a Department of Real Estate, Planning and Geoinformatics, School of Engineering, Aalto University, \\ P.O. Box 15800, 00076 Aalto, Finland
}

Received 14 September 2012; accepted 27 December 2012

\begin{abstract}
The trend of outsourcing operational property management services by the property owners has had a prominent role in the Finnish real estate sector. At the same time, value creation has been scattered across many players such as the owner, the property manager and several service providers. This paper aims to analyse the value creation practices and mechanisms between two partners, a real estate owner and its property management company, in order to assess the current value creation. The assessment is based on a lean partnering framework presented by Lamming (1993). The customers are office tenants in the Helsinki business district. The case findings showed that the expected customer value was challenging to deliver, because waste activities disrupted the value creation. The partners had also adapted some of the value creation practices differently, which caused turbulence in value creation. In addition, the partners had missed the power of doing improvements jointly, but prefer to use bidding to establish value creation. However, through lean thinking the organisations found a much-needed new approach to develop their partnership. The principles of lean management made the problem clearer and enabled the organisations to start dealing with the relevant challenges.
\end{abstract}

KEYWORDS: Value creation; Lean management; Waste; Continuous improvement; Partnership

REFERENCE to this paper should be made as follows: Jylhä, T.; Junnila, S. 2014. Partnership practices and their impact on value creation - reflections from lean management, International Journal of Strategic Property Management 18(1): 56-65.

\section{INRODUCTION}

The ultimate goal in lean management is to create value for the customer (e.g. Ballard et al. 2001; Womack, Jones 2003; Hines et al. 2004). In the real estate sector the value creation for the customers, for example for the users, has been scattered across many players: the owner offers the premises, the property manager manages daily value creation on the operational level, where several service providers deliver a spectrum of services. It can be assumed that the practices and process mechanisms between the many players have an impact on the effectiveness of value creation.

In lean management a lot of attention has been aimed at waste elimination but also at cooperation and partnering between the different players in order to enhance value creation. In the real es-

\footnotetext{
* Corresponding author. E-mail: tuuli.jylha@aalto.fi
}

tate sector, partnership is a widely used term, but sometimes it is left unclear to what the term partnership refers. Schniederjans et al. (2010) have noticed the same issues also in other sectors. Partnership has a variety of definitions and for example Ellram (1995) defined it as “....an on-going relationship between two organisations which involves a commitment over an extended time period, and a mutual sharing of the risks and rewards of the relationships". Macbeth's (1994) supplementing that partnership should be seen as a strategy and not just as a purchasing or procurement system.

Because the value creation in real estate sector is diffused, it is essential to acknowledge the impact of the partnering and cooperation practices and related process mechanisms on value creation. Therefore, in this paper value creation for the customer is studied in a partnership of two or- 
ganisations - a real estate owner and its property manager. The paper aims at describing the value creation practices and mechanisms between the two partners in order to assess the current value creation for the customer. The assessment is based on a framework adapted from Lamming (1993). The customers are the office users in the Helsinki central business district (CBD) and the two partners aim at creating value together for them. The primary data in the research is collected through face-to-face interviews and workshop discussions.

This paper is divided into five sections. Following the introduction, a description of partnering will be presented from a lean management perspective. The subsequent section then describes the research design. This is followed by an analysis of the results which focus on the case partnership and its value creation. The same frame that is introduced in the theory section will be used to present the partnership data. Finally, the implications arising from the results are drawn and conclusions are presented.

\section{VALUE CREATION IN A PARTNERSHIP}

Partnership is currently a regular term in the vocabulary of organisations in property markets. However, for a long time facility management (FM) service providers have been regarded merely as an expense with little motivation to develop the relationship with the FM service providers towards partnerships (Atkin, Brooks 2000). In general, partnership is seen to offer benefits such as asset and cost efficiencies, customer service enhancements, marketing advantages, and profit growth or stability (Lambert, Knemeyer 2004). However, Lehtonen and Salonen (2006) argue that in the Finnish property market the drivers for partnership are distinct to those usually mentioned in the literature. They found that partnering in FM services in Finland is merely based on (1) price and (2) reputation arising from prior work. In line with the conclusion of Lehtonen and Salonen (2006), Hui and Tsang (2004) stated that the aim of lower total cost is a more common practice than the other sourcing strategies. From lean management perspective, the previous studies do not offer a complementary view on the value creation in the real estate sector.

In the real estate sector the scattered value creation requires investment on cooperation and partnering among other things. Macbeth (1994) and Howell et al. (1996) have stated that a successful partnership cannot be achieved unless we change and revise our thinking and practices. Lamming (1993) was the first to describe what it takes to move beyond partnership (hereafter called lean partnering framework). In Table 1 a summary

Table 1. The role and nature of the nine factors in the lean partnering from value creation perspective (adapted from Lamming 1993)

The approach to

1. competition

2. prices

3. information exchange

4. sourcing

5. quality

6. R\&D

7. delivery practices

8. capacity management

9. pressure
What does it mean from a value creation perspective?

- Bidding does not support value creation in the long-term.

- Instead of bidding, continuous improvement maintain the dynamics between the partners and, thus, support value creation.

- Price reductions do not support value creation.

- Joint cost reductions support value creation.

- True transparency supports value creation.

- Two-way communication is necessary.

- Bidding and short-term relationships do not support continuous improvement and, thus, value creation.

- Re-sourcing is considered to be the last resort after all attempts to improve.

- Classical competition exists but in non-strategic activities.

- Partners aim to provide what customers require, not what the other partner wants them to provide.

- Those who implement continuous improvement strive for perfect quality and, thus, to enhance value creation.

- Doing R\&D together is a sign of collaboration to create value for the customer.

- True just-in-time both enhances and hastens value delivery.

- Synchronized capacity is a prerequisite for JIT deliveries.

- Pressure caused by other partners merely increases stress.

- Pressure imposed by the customer or the partner itself is applied to ensure continuous improvement and thus, enhances value creation. 
of the nine factors in the lean partnering are presented from value creation perspective and they are discussed afterwards.

The first factor of the lean partnering model of Lamming (1993) highlights that the competition through bidding and procurement systems is inappropriate. Traditionally, bidding has been seen as one of the central ways to ensure better service with lower costs, but Lamming (1993) describes that bidding does not guarantee better products or services, i.e., the customer does not necessarily perceive higher value through bidding. In lean partnership the main driver for better quality and lower costs is achieved through kaizen, a Japanese term that describes the principle of continuous improvement. In lean partnership common waste elimination offers a platform to do continuous improvement together.

Although bidding is not a default assumption in lean partnership, it does not mean that prices do not account. The second factor of the model emphasises that the real efficiency gains including lower prices can be achieved by cutting the actual costs together. Simply lowering prices does not mean that the actual costs are cut but this strategy strives to cut the margins of the service provider. From a value creation perspective, cost cutting - not price reduction - seeks to minimize waste and do the right things to keep the customer satisfied. To cut the actual costs requires open information exchange which is the third factor in the lean partnership. Information exchange is two-way, true, and confidential; the information cannot be used as a tactical weapon against the other partner (Lamming 1993).

The fourth factor highlights the basis of sourcing decisions. In the facility management context outsourcing and in-sourcing have always been a subject of debate (e.g. Atkin, Brooks 2000; Hui, Tsang 2004; Kadefors, Bröchner 2004). Sourcing in lean is usually based on long-term relationships that enable continuous improvement (Lamming 1993) and, thus, enhance value creation. According to Lamming (1993), bidding and short relationships usually do not support waste elimination and resourcing in lean is the last option after attempts at improvement. However, sourcing based on a classic competition does exist within non-strategic activities, but the sourcing to long-term relationships offers a more stable platform for developments and continuous improvement to both old and new partnerships.

The fifth factor is the approach to quality. Traditionally quality, according to Lamming (1993), is understood through the concept of mass production.
Quality is improved, for example, by increasing the number of inspectors or investing in a new process for reworks. From a value creation perspective this does not increase the absolute quality of the product but is another wasted task that is added into the process. How then to achieve higher quality? Lamming (1993) stressed that the guarantee for high quality is driven by continuous improvement with joint effort. If the drivers for continuous improvement exist, effort is aimed at joint waste elimination. However, as waste elimination does not increase customer value Lamming (1993) stated that joint research and design with product development and innovations is the most important link between the customers and the partners, who create that value. The attitude towards research and design provides the sixth factor of the lean partnership model.

The seventh factor describes delivery practices. Shingo (1989) stated that just-in-time (JIT) delivery system is a strategy to achieve non-stock or stockless production and, thus, reduce waste. Similarly, Lamming (1993) refers to JIT deliveries merely between the suppliers and the assembler. He highlighted that the JIT delivery should be true instead of merely moving the storages and buffers from one place to another. From the customer perspective, JIT delivery between the suppliers and assembler also entails shorter lead time to receive the customer value so it is not solely a value creation activity for the assembler. To take on the JIT delivery practice, the capacity of the different parties should be synchronised and in lean this is done together. Therefore, the management of the capacity is the eighth factor in Lamming's (1993) lean partnership.

The last factor in the model describes the role of pressure in the partnership. In lean partnership the pressure for improvements is high and it strives for continuous improvement (Lamming 1993) which is one of the key elements in value creation. Liker (2004) stated that in lean management organisations are guided to respect its partners by challenging and helping the partners to improve. However, the pressure is not caused by the other partner but rather is both self- and customer-imposed. Although both partners are pressured to improve and serve the customer, "the lean supplier should drive itself harder than the buyer does" (Lamming 1993).

\section{RESEARCH DESIGN}

This paper aims to analyse the value creation practices and mechanisms between two partners. The 
analysis is based on the lean partnering framework, which was presented in the theory section. Both partners, the real estate owner and its property management company, are major players in the Finnish property market: the real estate owner has over one million square meters of space with value of approx. 3 billion euros and the property management company is a nationwide service provider in the field of facility and property management. The customer, the office tenants in the Helsinki CBD, pays the highest office rents in Finland and were claimed to be one of the most demanding customers in Finland. Next, the research process with data collection steps is presented and some background information regarding the case partnership is provided.

\subsection{Data collection in the research process}

The study presented in this paper is part of a larger research project conducted in 2009-2012 in Finland. The research process of the case study is divided into nine phases. In the kick-of phase, the aim, scope, and customer were defined for the case study together with the two partners. After this four preliminary interviews (PRE) with the managers at the strategic level were conducted in order to gain a better understanding on the contractual relationships and power structures in the partnership. In the third phase, customer interviews (CU) were conducted with seven office tenants in the Helsinki CBD in order to understand what the customers expect. These expectations can be summarized as four points. Customers expected (1) fast service, (2) customer-oriented treatment that conveys the feeling of good service, (3) realtime information, and (4) easy access to contact people. In the next phase, value creation practices were gathered through 11 semi-structured interviews with the employees of the two partners, here called the employee interviews (EM). After these phases, the collected data from the phases three and four were organised and analysed. The preanalysed data was then presented, discussed and verified in the fifth phase, a first workshop (W1) with the partners. In the workshop a possibility to gather supplementary quantitative data (QD) on service requests was discussed and the data was later collected. After these phases the data was analysed further and the results of the analysis were presented in the second value workshop (W2) (the eighth phase). Finally, a post-analysis was conducted on the benefits of the case study and the case organisations described how they had perceived lean in closing interviews (CL).
When the data was collected, the interviews and workshops were not structured according to the lean partnering framework but the data, the descriptions of the daily work of employees and managers, was afterwards analysed in the framework context. In the data collection, special attention has been paid on the quality of the data: the same partnership practices have been studied through several data sets including quantitative and qualitative data. Most of the interviews have been conducted by two researchers and three to five researchers have facilitated the workshops where the data has been verified.

\subsection{The contractual relationships and the value delivering organisation}

Next, the partnership is described from two perspectives, both from a contractual one and from a value creation perspective. Fig. 1 illustrates the contractual relationships: the owner and the customer have signed the lease agreement and the property management company, as well as the service providers, have signed contractual agreements with the owner. The task of the property manager is to manage all external service providers.

If the relationships are visualized from the value creation perspective, the strategic and operational levels can be separated (Fig. 2). The strategic level is composed by people from both partners and they have established most of the practices that the operational level uses. The operational level includes the employees from the property manager company who are managing the value delivery and providing the feeling of good service to the customers. The external service providers deliver the actual repairs, maintenance and other services. There are at least two employees (one

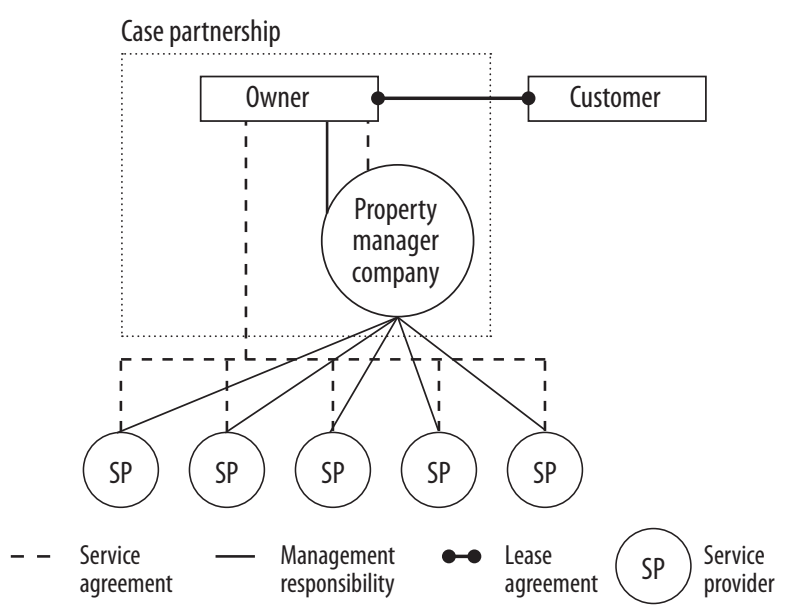

Fig. 1. The contractual relationships in the case partnership 


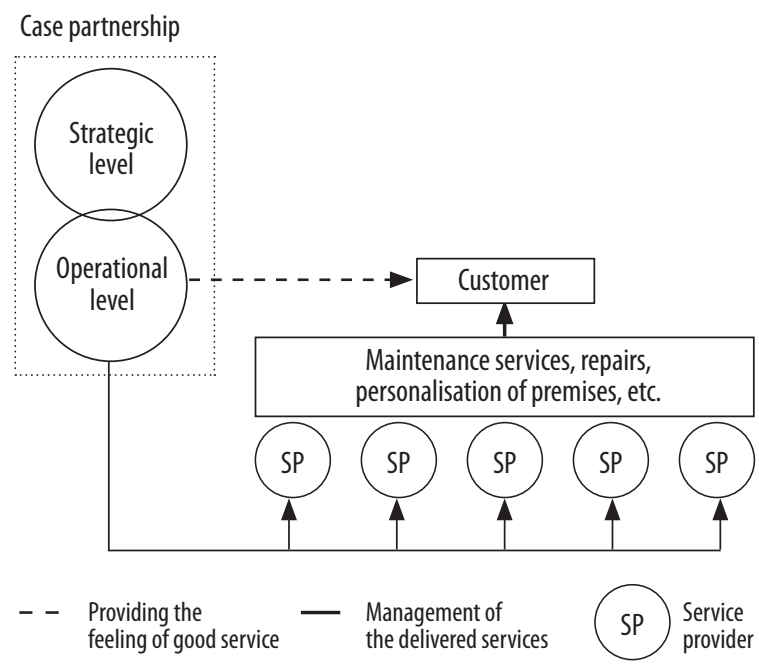

Fig. 2. The value delivering organisation

from the owner and one from the property management company) who are included on both of the levels as messengers.

In this paper the focus is on the partnership practices between the owner and its property management company (Fig. 1), i.e., on the practices that the strategic level invents and the operational level subsequently makes a reality (Fig. 2). These practices aim at creating customer value for the customer.

\section{RESULTS}

In this chapter, the case partnership practices discussed in the interviews and workshops are presented through the lean partnering framework adapted from Lamming (1993). Table 2 summarises the results in the framework, and shows which of the data sources the results are based on. Afterwards the partnership practices are discussed factor after factor.

The approach to competition. Regarding competition, bidding and related practices were discussed in all the phases of case study. According to the preliminary interviews on the strategic level, the case partnership was established through bidding based on the idea of true partnership and joint value creation, not solely on competition. Unfortunately, as the employees described it, the true partnership was not fully materialized on the operational level: the employees on the operational level felt that they do not have an equal standing in the partnership. In other words, they felt that they do not have the power to create value for the customer efficiently as they see it but more of an obligation to follow the bidding procedures and goals that are set by the strategic level. For exam- ple, if a customer complains on broken window, the employees felt that they are not allowed to order a repair by the fastest track, but obligated to follow a time-consuming bidding procedure. This kind of outcome has a dramatic impact on value creation.

On the operational level, a lot of daily tasks were arranged through bidding. According to all the employee interviews, bidding was implemented in all kind of services: for a single activity and a continual activity, for a small repair and a big repair, for a budgeted and non-budgeted service, etc. According to lean thinking, continuous bidding does not support continuous improvement and thus, value creation for the customer. All the employees on the operational level described that the constant bidding frustrated them especially when dealing with small, single repairs. For example, the employee interviews and the quantitative data showed that a lot of time was spending on purchasing services with the lowest possible cost: the procurement process for a 100 EUR service and for a 100000 EUR service was the same. Due to the inflexible procedure, the actual transaction costs might even exceed the actual service costs. The employees on the operational level also found it challenging to ask bids for small repairs because the FM service providers were unwilling to give them, thus, value creation for the customer was delayed. However, later some improvements were implemented. In the first workshop, the strategic level noticed the problem and initiated a new practice to streamline the process: the employees on the operational level were allowed to directly order the repair from a FM service provider, who was a member of the established partnership network. The visibility of the problem on both levels contributed to improvements being made.

The approach to prices. When reflecting the discussions and interviews towards this factor, it is clear that the difference between prices and costs was not clear to the interviewees and workshop participants. In most of the interviews on the strategic and operational levels the interviewees described their perception of prices that were stated to be continuously increasing. Based on the preliminary interviews and workshops, the strategic level has seen the partner network as an antidote for price increases. Therefore, the owner has established a large partner network through bidding competition. According to the employee interviews, strategic level also instructed them to use bidding to minimise prices. However, because bidding does not guarantee cost minimisation, a mechanism that would actually impact on cost minimisation 
Table 2. The relationship factors in the case partnership from a value creation perspective and the sources of the results: (PRE) preliminary interviews, (CU) customer interviews, (EM) employee interviews, (W1) first workshop, (QD) quantitive data, (W2) second workshop, and (CL) closing interviews

\begin{tabular}{|c|c|c|c|}
\hline \multicolumn{2}{|c|}{ The approach to } & \multirow{2}{*}{$\begin{array}{l}\text { What it means from value creation per- } \\
\text { spective (adapted from Lamming 1993) } \\
\text { - Bidding does not support value creation } \\
\text { in the long-term. } \\
\text { - Instead of bidding, continuous improve- } \\
\text { ment maintain the dynamics between } \\
\text { the partners and thus, support value } \\
\text { creation. }\end{array}$} & \multirow{2}{*}{$\begin{array}{l}\text { In the case partnership } \\
\text { - The strategic level aimed to establish true partner- } \\
\text { ship to enhance value creation (PRE). The plan did } \\
\text { not materialize on the operational level (EM). } \\
\text { - The heavy use of bidding did not support value crea- } \\
\text { tion on the operational level (EM, QD). }\end{array}$} \\
\hline 1. & con & & \\
\hline 2. & prices & $\begin{array}{l}\text { - Price reductions do not support value } \\
\text { creation. } \\
\text { - Joint cost reductions support value cre- } \\
\text { ation. }\end{array}$ & $\begin{array}{l}\text { - Prices were managed, but not costs: } \\
\text { - The owner has established partnership networks } \\
\text { to keep the prices stable (PRE, W1, W2). } \\
\text { - The operational level mainly kept the prices down } \\
\text { through bidding (EM). }\end{array}$ \\
\hline 3. & $\begin{array}{l}\text { information } \\
\text { exchange }\end{array}$ & $\begin{array}{l}\text { - True transparency supports value crea- } \\
\text { tion. } \\
\text { - Two-way communication is necessary. }\end{array}$ & $\begin{array}{l}\text { - Everybody agreed that the information is not trans- } \\
\text { parent (EM, W1, W2, CL). } \\
\text { - The information was not always communicated: the } \\
\text { operational level felt that the information is given } \\
\text { to be followed (EM) and the strategic level found that } \\
\text { information guides the strategic and operational } \\
\text { levels to do things in different ways (W1, W2). }\end{array}$ \\
\hline 4. & sourcing & $\begin{array}{l}\text { - Bidding and short-term relationships } \\
\text { do not support continuous improvement } \\
\text { and, thus, value creation. } \\
\text { - Re-sourcing is considered to be the last } \\
\text { resort after attempts to improve. } \\
\text { - Classical competition exists but in non- } \\
\text { strategic activities. }\end{array}$ & $\begin{array}{l}\text { - Outsourcing with bidding competition played a piv- } \\
\text { otal role in sourcing decisions (EM, W1, W2). } \\
\text { - The strategic level was interested at developing re- } \\
\text { lationship networks to improve value creation (PRE, } \\
\text { W1, W2, CL). }\end{array}$ \\
\hline 5. & quality & $\begin{array}{l}\text { - The partners aim to provide what cus- } \\
\text { tomers require, not what the other part- } \\
\text { ner wants them to provide. } \\
\text { - Those who implement continuous im- } \\
\text { provement strive for perfect quality } \\
\text { and, thus, to enhance value creation. }\end{array}$ & $\begin{array}{l}\text { - All strived to have satisfied customers, but at the } \\
\text { same time all were concerned whether there were } \\
\text { enough resources for this to become a reality (PRE, } \\
\text { EM, W1, W1, CL). } \\
\text { - The structures for joint improvements did exist, but } \\
\text { the culture and attitudes pushed for solo problem } \\
\text { solving (EM). }\end{array}$ \\
\hline 6. & $\mathrm{R} \& \mathrm{D}$ & $\begin{array}{l}\text { - Doing R\&D together is a sign of collabo- } \\
\text { ration to create value for the customer. }\end{array}$ & - The partners had few joint R\&D projects (W1, W2, CL). \\
\hline & $\begin{array}{l}\text { delivery prac- } \\
\text { tices }\end{array}$ & $\begin{array}{l}\text { - True just-in-time delivery both enhanc- } \\
\text { es and hastens value delivery. }\end{array}$ & $\begin{array}{l}\text { - Value creation was enhanced by way of physical } \\
\text { proximity to the customers (EM, W1). } \\
\text { - Operational level had no efficient tools to manage } \\
\text { just-in-time deliveries (CU, QD). }\end{array}$ \\
\hline 8. & capacity mgmt. & $\begin{array}{l}\text { - Synchronized capacity is a prerequisite } \\
\text { for JIT deliveries. }\end{array}$ & $\begin{array}{l}\text { - Both partners did their own capacity planning and, } \\
\text { thus, the capacities were not synchronized (EM, W1, } \\
\text { W2, CL). }\end{array}$ \\
\hline & pressure & $\begin{array}{l}\text { - Pressure caused by other partners } \\
\text { merely increases the stress. } \\
\text { - Pressure caused by the customer or the } \\
\text { partner itself strives for continuous im- } \\
\text { provement and thus, enhances value } \\
\text { creation. }\end{array}$ & $\begin{array}{l}\text { - Extra-demanding customers created a lot of pres- } \\
\text { sure for both partners (PRE, CU, EM, W1, W2, CL). } \\
\text { - The workload, especially on the operational level, } \\
\text { was heavy (EM, W1, W2). } \\
\text { - The pressure on the operational level was not solely } \\
\text { self-imposed or customer-imposed (EM). }\end{array}$ \\
\hline
\end{tabular}

could not be identified. This indicates that actual costs are not reduced, but merely the prices are managed.

The approach to information exchange. Related to information, the key observation was that information was not transparent. This was also admitted by the strategic and operational levels in the employee interviews, workshops and closing interviews. The employees on the operational level felt that the information is not always up for discussion, but rather to be absorbed and followed. For example, the employees on the operational level described that ad hoc phone calls were established to first inform the strategic level and second to re- 
ceive decisions that were made by the other partner. On the other hand, during the workshops the strategic level noticed that although information is exchanged, the information guides the strategic and operational levels to do things in different ways. This generates a challenge to create value jointly. For example, in the later phases of the case, it was found out that the employees of the property management company have used a wrong procedure among certain kind of purchases. Because of this the operational level had carried out a lot of wasteful activities such as preparing and searching for information for the service providers. This confusion was solved via two-way communication.

The basis of sourcing decisions. With this factor the discussion was heavily focused on outsourcing that was conducted either by bidding or through partnership networks. Most of the FM services, such as cleaning and maintenance, were outsourced i.e. they were provided by someone other than the property manager or the owner. Based on the descriptions of the employees on the operational level, the tool to organize value creation was bidding and the service providers were selected based on the lowest price. As already mentioned, because an improvement has been done later in the case, nowadays the operational level has another mechanism to sourcing in small, single repairs: they can select the service provider within the partnership network without bidding. In the workshops the managers on the strategic level showed their interest in developing the partnership networks, instead of solely relying on bidding.

The approach to quality. There were two issues that were discussed relating to this factor. First, all the interviewees on the strategic and operational levels were worried about how time and resources on the operational level suffice to exceed the expectations of the customer because of the demanding customer and the current challenges to meeting their daily expectations. At the same time the same interviewees wanted to improve the quality of their existing services and streamline the current value creation processes for example by cutting down the lead times and clarifying communication. However, the actions of attempted improvement implementation were similar to those in mass-production: extra checkpoints for quality control, supplements to the authorization process of the operational level, and more fixed criteria in bidding. Although the intentions were good, many of the actions are not in line with lean management. The checkpoints create a lot of delays and duplications, the authorization process is structured according to the needs of the owner (not those of the customer), and bidding does not support continuous improvement. Second, according to the employee interviews and workshop discussion, structures for higher quality through continuous improvement do exist, such as weekly meetings, but the working with the improvement was not done together. In other words, the employees described that the improvements and solutions for problems were invented alone and, thus, some improvement potential could have been missed. However, despite the challenges the partners have shown an interest on joint improvements in the workshops. Hopefully the nascent interest in continuous improvement will be strengthened.

The approach to $R \& D$. Relating to this factor it was found out that the partners have only few activities for joint R\&D (for example this project). According to the workshops and closing interviews, the partners had jointly decided that the improvement effort and energy in their partnership will be primarily aimed at developing the current value creation practices before starting to establish new service platforms or support services. At the same time, managers on both sides described in the workshops or closing interviews their own development projects for example, adjusting their business strategy with customer commitment or establishing new service concepts.

Delivery practices. Within this factor, the discussion pinpointed the challenges relating to JIT deliveries but also an opportunity that was utilised. The opportunity was the close physical proximity to customer: the operational level was located near the tenants and their offices. Although Lamming (1993) stated that just-in-time deliveries do not necessarily require close geographical proximity, in this case it supported value creation for the customers. Otherwise there were a lot of challenges that were not supporting just-in-time deliveries. The sample of requests and related lead times - the time from when the request is given to the time the acknowledgement is given - from a seven-month period shows that JIT deliveries cannot be guaranteed, although in general lead times were relatively short; approximately 60 per cent of the cases have a lead time of 7 days or less. A deeper analysis of the lead times shows the variations. For example, the lead time of taking care of the request related to lighting was from less than 1 day up to 126 days. However, the data does not provide the exact figures because the time when the acknowledgement is given varies. According 
to employee interviews, this has caused another JIT delivery problem for the operational level because they had no efficient tools to follow when the value adding work, e.g., fixing the lighting, is conducted.

The approach to capacity management. The key observation that was made under this factor was that the partners did not plan the capacity management together. Managers in the workshops and most of the employees in the interviews agreed that capacity planning is best designated as independent tasks of the partners. Although a lack of capacity was a problem also for the other partner, the previous partner was solely responsible for solving it. In lean partnering, capacity planning is conducted together.

The level of pressure. In general the amount of pressure was found out to be high. In all the data collection phases (except in the quantitative data collection phase), a pressure to satisfy the customer, i.e., the tenant organisation and the individual users, was discussed. The pressure from the customer was especially an issue for discussion because in this case they were found to be supremely demanding. Although the operational level had a key role in daily value delivery, the discussion especially in the workshops pinpointed that the strategic level also received direct pressure from the customer because the demanding tenant could easily dismiss the statements of the operational level and contact the strategic level to fulfil their wishes. For example, a top manager in a customer organisation could easily contact the top manager of the owner organisation.

According to the employee interviews and workshop discussions, the property manager company had also a high pressure to satisfy the other partner, the owner. In the preliminary interviews the fact that the service agreement, which was the basis for the partnership, was fixed for a short period of time and both partners were well aware of it. The owner had the strain to make decisions that it thinks are best for enhancing value delivery for the customers in the future. Unfortunately, according to the lean partnering model this kind of pressure, which is neither self- nor customer-imposed, does not support continuous improvement and thus, value creation between the partners.

\section{OBSERVATIONS FROM THE CASE}

Three general implications can be drawn from the case. First, there were many waste activities that hindered and even blocked value creation in the case. For example the high volume of bidding caused delays and non-transparent information caused an extra workload. Second, the data showed that the strategic and operational levels had adopted the agreed-upon practices differently, which caused a lot of extra turbulence and waste activities into the operations and processes and thus, the expected customer value was challenging to deliver. Based on this research, it cannot be pinpointed why the agreed-upon practices were adopted so differently. However, without a common way of thinking and making the problems visible to all, the partnership practices were seen as challenging to improve. Therefore, the value creation principles suggested by the research team to the partners highlighted the role of creating a common understanding on the topic, making the challenges visible to all and developing best practices jointly between the partners and the different levels (strategic and operational).

Third, in addition to the process flow and the waste in it, another key element from lean management was missing: continuous improvement. Although employees and managers were trying to enhance value creation through improvements and development projects, the root problems were not solved. In lean management continuous improvement are the engine that generates the aspiration for more efficient and effective value creation. In the case a lot of confidence was placed on bidding, which was seen as a key tool to survive and to establish value creation.

Although the lean partnering framework unveiled many issues that were hindering the value creation, the framework fails to discuss the actual customer value. On the strategic level in the case, lean pushed the organizations to develop their thinking with an eye on customer value. Traditionally in property markets a lot of effort has been aimed at the property to keep the value of the asset high, although the end-user services have also gained more and more attention as a means of delivering customer value. In addition to products and services, it is possible to add a third value creation aspect. Vargo et al. (2008) introduced the idea of value-in-use. When applying the ideas behind value-in-use it can be argued that the value of premises is not delivered to the customer at the time of signing the lease agreement, but at the time the premises are used. Posing a similar kind of idea to that of Vargo et al. (2008), Pine and Gilmore (2011) introduced experiences as a source to deliver value for the customers. The experiences are gained when the product or service is in use. 
This kind of new strategic thinking was adapted along the research process. Although the new mode of thinking is currently in its starting position in the case partnership, the ideas discussed in the interviews with the operational level indicate that this kind of thinking could also be well adapted also on the operational level.

During the research process, the strategic level became especially aware of the challenges on the operational level and some clarifications could be established to streamline the process. Lean management assisted the organisations in finding a new approach to developing their partnership by showing the challenges from a new viewpoint. Although many of the ideas that were discussed with the partners could have been solved without the ideas of lean, the new way of thinking offered a more objective platform to start dealing with the issues.

\section{CONCLUSIONS}

In this paper a special focus was placed upon the value creation practices and process mechanisms in a partnership of two organisations - the property owner and its property management company. This paper analyses the value creation practices and mechanisms between the owner and property manager and evaluates current value creation for the customers. The evaluation is done based on a lean partnering framework adapted from Lamming (1993). The primary data on the current value creation practices and process mechanisms were collected through workshops and semi-structured interviews.

The findings can be summarised by three points. First, the findings showed that there was a great deal of waste activities which were hindering the value creation. The great amount of waste and its universality indicates that this might not be the only case with these kinds of challenges. Second, the findings pinpointed that the partners had adopted some of the value creation practices differently and it clearly caused a lot of turbulence and waste in value creation: "the boat ran into each shoal along the way". Third, continuous improvement, one of the key elements of lean management, was missing. Although employees and managers were trying to enhance value creation through improvements and development projects, the root problems were not solved. In lean management continuous improvement is the engine that generates the aspiration for more efficient and effective value creation. In the case a lot of confidence was placed on bidding, which was seen as a key tool to survive and to establish value creation.

The most significant disadvantage caused by the current practices and procedures was that the customers did not get the value that would have satisfied them. However, during the research project some improvements and clarifications were able to be implemented because the issues were finally visible to both partners. The value creation perspective adopted from lean management pushed the organisation to put more effort into delivering the required customer value and recognising the inefficiency that the waste activities caused. Although many of the ideas from lean thinking can be implemented and used without being lean conscious, the new approach assisted the companies in dealing with the identified challenges although the process flow remained missing.

The case study nature of the research implies some limitations. However, the aim is not to generalise the results of the case study, but to analyse and evaluate the current partnership practices. For this purpose, single-case study strategy provides a solid approach to reach the aim. Because of the limitations, more studies on true partnerships and partnering networks, for example according to lean management, are needed in the future. There is inevitably wasted potential if the benefits of true partnerships remain out of reach.

\section{ACKNOWLEDGEMENT}

The authors would like to thank Professor Edward Finch for his valuable support and co-operation in this research.

Tuuli Jylhä thanks Finnish Foundation for Technology Promotion, Doctoral Programme of Aalto University of School of Engineering, Confederation of Finnish Construction Industries, the Finnish Funding Agency for Technology and Innovation, KIINKO Real Estate Education and Finnish Association of Geodetic and Land Surveyors for financial support.

\section{REFERENCES}

Atkin, B.; Brooks, A. 2000. Total facilities management. Cornwall: Blackwell Science, MPG Books Ltd.

Ballard, G.; Koskela, L.; Howell, G.; Zabelle, T. 2001. Production system design in construction, in Proceedings of the $9^{\text {th }}$ annual conference of the International Group of Lean Construction, 6-8 August, 2001, Singapore.

Ellram, L. 1995. Partnering pitfalls and success factors, International Journal of Purchasing and Materials 
Management 31(1): 35-44. http://dx.doi.org/10.1111/ j.1745-493X.1995.tb00201.x

Hines, P.; Holweg, M.; Rich, N. 2004. Learning to evolve: a review of contemporary lean thinking, International Journal of Operations \& Production Management 24(10): 994-1011. http://dx.doi. org/10.1108/01443570410558049

Howell, G.; Miles, R.; Fehlig, C.; Ballard, G. 1996. Beyond partnering towards a new approach to project management, in Proceedings of the $4^{\text {th }}$ annual conference of the International Group of Lean Construction, August, 1996, Birmingham, UK.

Hui, E. Y. Y.; Tsang, A. H. C. 2004. Sourcing strategies of facilities management, Journal of Quality in Maintenance Engineering 10(2): 85-92. http://dx.doi. org/10.1108/13552510410539169

Kadefors, A.; Bröchner, J. 2004. Building users, owners and service providers: new relations and their effects, Facilities 22(11/12): 278-283. http://dx.doi. org/10.1108/02632770410561268

Lambert, D. M.; Knemeyer, A. M. 2004. We're in this together, Harvard Business Review 82(12): 114-122.

Lamming, R. 1993. Beyond partnership - strategies for innovation and lean supply. Cornwall: Prentice Hall.

Lehtonen, T.; Salonen, A. 2006. An empirical investigation of procurement trends and partnership management in FM services - a Finnish survey, International Journal of Strategic Property Manage- ment 10(2): 65-78. http://dx.doi.org/10.1080/164871 5X.2006.9637545

Liker, J. K. 2004. The Toyota way - 14 management principles from the world's greatest manufacturer. New York: McGraw-Hill.

Macbeth, D. K. 1994. The role of purchasing in a partnering relationship, European Journal of Purchasing and Supply Management 1(1): 19-25. http://dx.doi. org/10.1016/0969-7012(94)90039-6

Pine II, J. B.; Gilmore, J. H. 2011. The experience economy, updated edition. Boston, Massachusetts: Harvard Business Review Press.

Schniederjans, M. J.; Schniederjans, D. G.; Schniederjans, A. M. 2010. Topics in lean supply chain management. Singapore: World Scientific, Mainland Press Pte Ltd.

Shingo, S. 1989. A study of the Toyota production system - from industrial engineering viewpoint, revised edition, translated by Dillon. Cambridge: Productivity Press.

Vargo, S.; Maglio, P.; Akaka, M. 2008. On value and value co-creation: a service systems and service logic perspective, European Management Journal 26(3): 145-152. http://dx.doi.org/10.1016/j.emj.2008.04.003

Womack, J. P.; Jones, D. T. 2003. Lean thinking: banish waste and create wealth in your corporation. New York: Free Press. 